\title{
A GIS OF SARDINIA'S COASTAL DEFENSE SYSTEM (XVI - XVIII CENTURY)
}

\author{
M. Deidda ${ }^{\text {a }}$, C. Musa ${ }^{\text {b }}$, G. Vacca ${ }^{a}$ \\ ${ }^{a}$ DICAAR, Department of Civil and Environmental Engineering and Architecture, University of Cagliari \\ P.zza D’Armi - 09123 Cagliari, Italy vaccag@unica.it \\ ${ }^{\mathrm{b}}$ Engineer
}

Commission II WG II/6, WG II/7; Commission IV WG IV/2

KEY WORDS: GIS, Sardinia Coastal Defense System, Geospatial Analysis, Conservation, Documentation

\section{ABSTRACT:}

The use of GIS as a tool for archival, analysis and representation of geographic information has become significantly popular in many scientific fields that are directly concerned with the "territory" as their object of study. The field of application of GIS, however, has expanded also in other areas, such as those related to humanities and architecture, in which the territory is studied in an "indirect" mode because it constitutes a kind of substrate on which to develop a specific spatial analysis for particular purposes. Among these areas are to be included certainly archeology and restoration, fields in which the GIS has become a useful tool for historical studies.

In this work we present a GIS developed for the study of the historical and territorial coastal defense system of Sardinia $\left(16^{\text {th }}-18^{\text {th }}\right.$ century), in order to respond to the need to store, analyze and efficiently manage the information regarding cultural heritage and landscape heritage such as that consisting of the coastal defensive towers of Sardinia. This defensive system, in fact, was composed by over 100 towers positioned around the entire coastal perimeter of Sardinia, of which more than 90 still exist today. Their position was planned on the basis of the following criteria:

- Warning the neighboring towers about the sighting of enemy ships

- Protecting coasts located near the towns

- Monitoring the water sources near the coast

- Allowing for the full visibility of the coasts of any morphology

With this study we also verified, through the use of high resolution and high accuracy DTM (LiDAR) and the topographic databases, whether the positioning criteria specified in the design of the system were respected and effective.

\section{INTRODUCTION}

The use of GIS as a tool for archival, analysis and representation of geographic information has become significantly popular in many scientific fields that are directly concerned with the "territory" as their object of study. The field of application of GIS, however, has expanded also in other fields, such as those related to humanities and architecture, in which the territory is studied in an "indirect" mode because it constitutes a kind of substrate on which to develop a set spatial analysis for their own purposes. In particular, documentation is of fundamental importance in the field of conservation and promotion of the historical and architectural assets. Indeed, it has the twin purposes of recording the interventions performed to insure the integrity and conservation of the asset, and archiving the knowledge (historical chronology, state of conservation, material analysis, etc.) that's useful for the management. Promotion and fruition of the same assets. These data are thus the basis for any conservation, restoration and promotion policy and have the purpose of acquiring all information useful to understand its value, and providing tools for managing transformation and development of the asset and for disseminating information in order to involve the sociocultural context in the promotion process.

In order to exploit the great potential of the documentation regarding the historical-architectural assets, these data are organized in databases linked to a Geographical Information System. The rapid diffusion of GIS in the field of the protection and promotion of cultural assets is also due to their foremost feature, that is, having a series of tools for the integrated management of spatial and thematic information allowing for a more efficient planning of the development policies involving the assets.

Thus, if on one side the GIS for the cultural assets represents an important tool for the planning of all policies of promotion of a territory, in its wider meaning of "cultural landscape", on the other it allows for both wider and more focused analysis leading to a deeper knowledge of system of the cultural assets of a territory.

A GIS has important potential applications for the main processes of cultural assets management. These processes are:

- $\quad$ research of documentation about the asset;

- $\quad$ analysis of the conservation status of the asset;

- decision of the conservation and management strategies;

- implementation of the monitoring and promotion policies.

The work presented here concerns a GIS designed for documenting, promoting and studying the coastal defense system built in Sardinia between the $16^{\text {th }}$ and $18^{\text {th }}$ century. The capabilities of the GIS have been used to verify the compliance and efficacy of the system with respect to its original requisites. The system in fact had specific criteria of positioning and visibility so that, in case of an attack, it would be possible to alert the population and prepare a defence. 


\section{THE COASTAL DEFENCE SYSTEM OF SARDINIA $\left(16^{\mathrm{TH}}-18^{\mathrm{TH}}\right.$ CENTURY)}

Because of its insularity and central position in the Mediterranean, Sardinia was often the target of invasion and foreign occupation in the course of history; in particular in the $16^{\text {th }}$ century, which sees the rise of the Ottoman empire as a Mediterranean power. The island, although not at the forefront of the political scenery in the first half of the century, still had an important role in the tactical theatre of the Spanish empire because, with its location, it was a natural rallying point for expeditions to the northern regions of Africa contended with the Turkish enemy. These Barbary states became the theatre of several battles between the soldiers of the Crown of Spain and the subjects of Suleiman the Magnificent, with alternating outcomes.

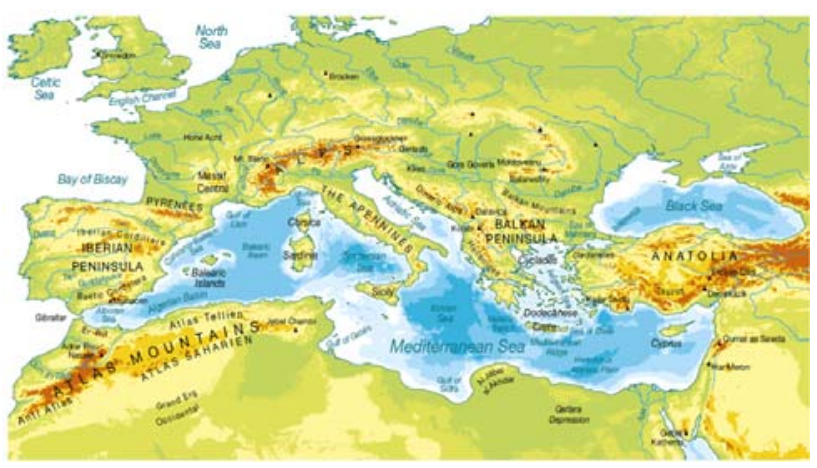

Figure 1: Map of the Mediterranean Sea

It's no coincidence that, just at the end of the $16^{\text {th }}$ century, the king of Spain decided to complete the existing coastal defence system in Sardinia with new towers, organizing it under the “Towers Administration" or "Royal Administration". Under the direction of captain Camos first, and then viceroy De Moncada, a coastal defence system of about one hundred towers was designed, also including the pre-existing towers. Examination of Camos' and De Moncada's projects evidences that, in the geographical planning of the defence system, le location of each site was not chosen because of a regular spread (that is, keeping a somewhat constant distance between the towers), but but because of the system's main purpose, thus expressed:

1. Watch over the coast near the urban areas, and especially giving the population time to run away before the arrival of raiders. Such time corresponded to the time a ship would take to cross a sea span equal to the visual range of the watch point. This range was about $12-13 \mathrm{~km}$ for a tower on a beach, with a watch post height of 11-12 $\mathrm{m}$ (the worst case).

2. Provide a continuous and uninterrupted flow of information about sightings, both to the nearest towers and to the nearby inhabited areas. Each tower could do a direct sighting or an indirect one (when relayed from another tower); indirect sighting required the intervisibility of nearby towers, but gave the population more time to prepare in case of attack.

3. Guard every place where it was possible to go ashore in order to stock up fresh water (river mouths, fountains, springs...) in order to reduce the autonomy of corsair ships.
4. Watch over promontories, coves, coastal caves, and anything that could hide ships from sights, in order to prevent ambushes to commercial shipping (which sailed within 2-3 miles from the coast)

There were several architectural models used in the construction of coastal towers. In Sardinia the truncated-cone model was mainly used, with dimensions determined by the military and functional requirements. Functionally, the towers were classified as "watch" or "defence". The former ("watch towers") were of small size, 4 to $10 \mathrm{~m}$ in diameter by 7 to $12 \mathrm{~m}$ in height. They were manned by up to three guards. Defence towers were larger, with diameter between 9 and $21 \mathrm{~m}$ (usually about 12) and heights of 12 to $18 \mathrm{~m}$. They had a command role and could accommodate up to eight men. In the figure 2 the example of Sarralà tower: plant, section and facade of the tower.
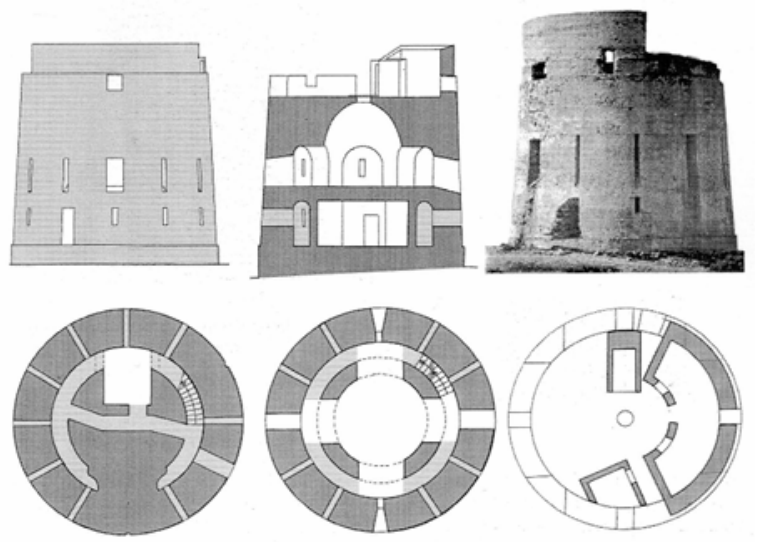

Figure 2: Sarralà Coastal Tower

\subsection{Determination of the "Royal Administration" coastal defence system}

In order to build the GIS it was necessary first to determine the main elements of the system, that is, the "true" coastal towers. Indeed, sometimes buildings that never had any coastal defence purpose have been mistakenly considered as watch towers of the "Royal Administration". In this phase of the study, information was gathered from the "Towers Administration" and "Secretariat of State and War" funds of the State Archive of Cagliari. In this way 113 towers were located, 16 of which no longer present on the territory. It must also be noted that not all the coastal towers were active at the same time; some were abandoned due to obsolescence or to the presence nearby of new towers, better armed and with a larger visual range. The total number of active towers at any one time ranged between 64 and 80.

\section{THE GEOGRAPHIC INFORMATION SYSTEM OF THE COASTAL DEFENCE SYSTEM}

The first task in the construction of the GIS was determining the geographic locations of all the towers. The datum used is the one in use in Italy, that is ETRF2000 (number 6709 in the EPSG catalogue). The planar and vertical coordinates of the 113 towers were determined using the 1:10000 scale CTR (Regional Technical Map), the 1:2000 ortophoto of the coast of Sardinia, and the information supplied by the historian E. Altara (from "Guida alle torri costiere della Sardegna", Cortona 2007, 
reporting the geographic coordinates of all the towers). Figure 3 shows the location of the towers which were part of the coastal defence system. Figures 4 and 5 are pictures of two coastal towers.

Building the GIS required the input of data related to the census of the towers, such as their name, location, conservation state, defensive type, dimensions, form type, date of construction and dates of subsequent interventions. To the data of each tower were also linked photos and designs thereof.

An essential data item for the verification of the requisites imposed by the original defensive design, and in particular on the visual range that had to cover the other towers, the coves and the water sources, was obviously the height of each tower. Determining these heights was a difficult prospect since:

1. Many towers don't have at the present time the original height. Some have in part collapsed while others have been subjected to extensive structural modifications.

2. Some towers have been completely destroyed, and we don't know their geometric characteristics.

3. The historical documentation regarding the towers is limited and incomplete. Also, we must remark that most bibliographic sources report the total heights (including the parapet) whereas only rarely they report those at the "platform", that is, the ones from where the guards would look.

4. The foundation of some towers is on a slope, thus it would be necessary to distinguish between an "upper side" and "lower side" height.

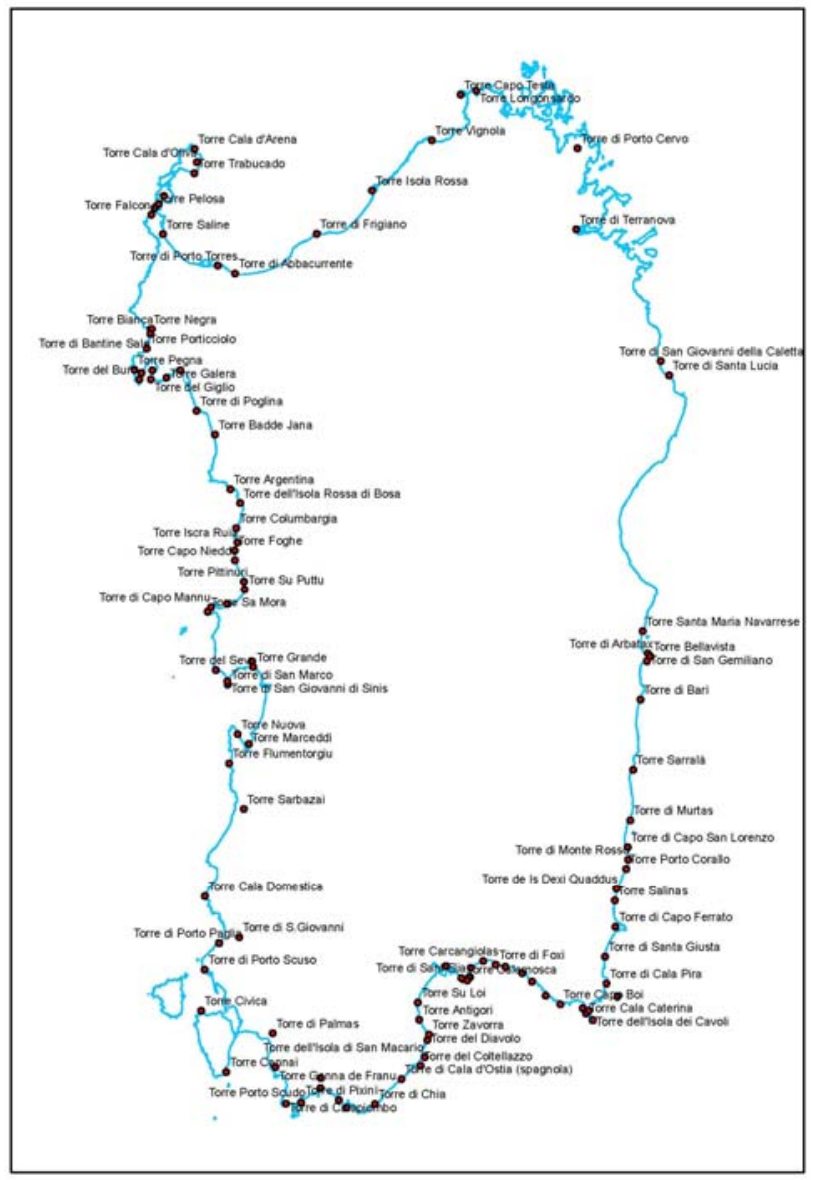

Figure 3: Sardinia coastal defence system

For the destroyed and modified towers a conventional height of $8 \mathrm{~m}$ was used. For those on a slope, the height was calculated as the average of the "upper side" and "lower side" heights. In all other cases, both the total height and the platform height have been recorded in the database. The platform height is the one that was used in the visibility analysis.

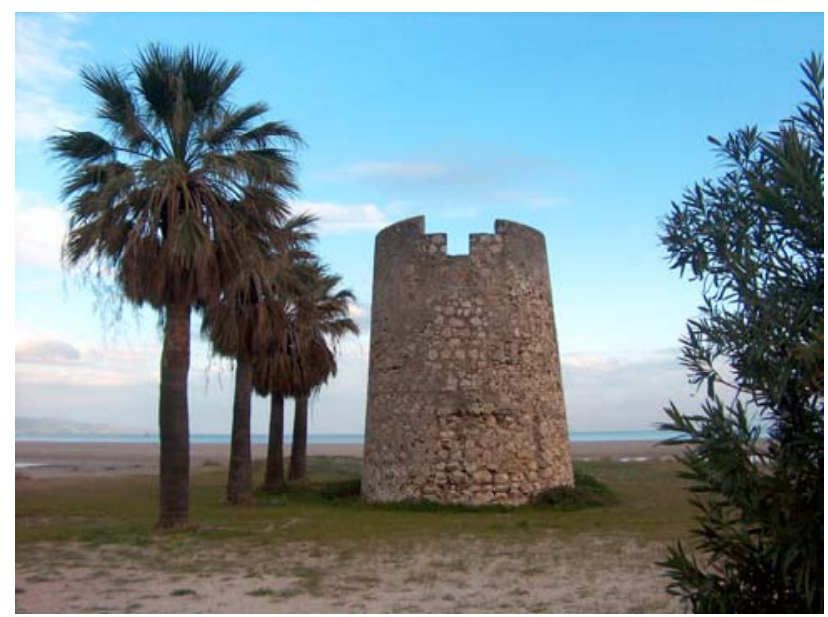

Figure 4: Poetto Coastal Tower

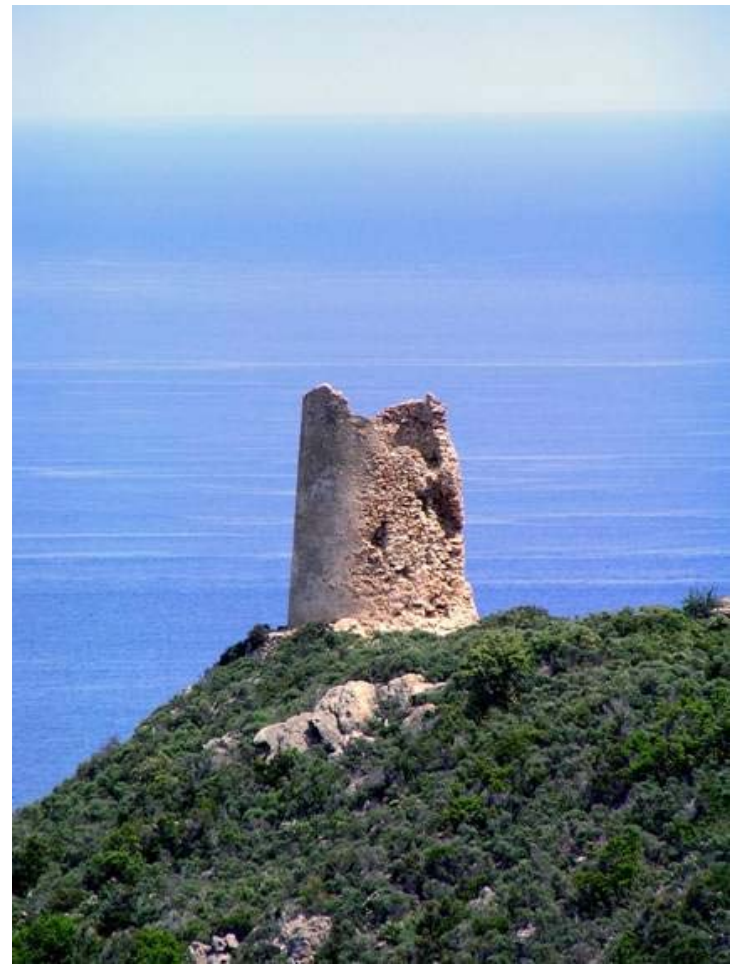

Figure 5: San Lorenzo Coastal Tower

\subsection{Input data and software}

The software used for verifying the correspondence of the coastal defence system to the design requisites is ArcGIS 10.3. The input data were organized in one ArcGIS geodatabase, thus organized:

- the file Total_Tower_ETRF2000_3D.shp, containing the geometry and data of the coastal defence towers system; 
- $\quad$ the DTM (Digital Terrain Model) of the coastal band of Sardinia, with $5 \mathrm{~m}$ resolution, obtained from a LiDAR survey with at least 1 sample per square meter;

- the file DBT_emergenzanaturaleacqua.shp, a point shapefile containing springs, water sources, and river mouths on the coastal band, extracted from the 1:10000 digital cartography of the regional administration of Sardinia.

\section{GEOSPATIAL ANALYSIS}

Having built the geodatabase of the coastal defence system, we started verifying the design requisites of the system as reported in par. 2. In particular we wanted to test the potential and functionality of the tools offered by the GIS software in suport of the study and analysis performed by historians and experts of historical-architectural assets.

In this stage, thus, the geospatial conditions of the towers were checked with respect to:

1. intervisibility between neighbouring towers;

2. control over the coastal water sources where corsair ships could renew their water supply;

3. control over all coves and inlets where corsair ships could hide.

We on the other hand overlooked the requisite of a 12-13 km line of sight out to the sea, which is always fulfilled.

\subsection{Intervisibility between neighbouring towers}

For this kind of verification we implemented an automated procedure using the Visibility tool in the Python language, and a manual one using the Line of Sight tool. The Visibility tool determines the raster surface locations visible to a set of observer features, or identifies which observer points are visible from each raster surface location.

The Line Of Sight tool calculates intervisibility between the first and last vertex of each line feature given its position in $3 \mathrm{D}$ space relative to the obstructions provided by a DTM. The first vertex defines the observation point, whereas the last is the observation target.

The data used in this analysis are:

- Total_Tower_ETRF2000_3D.shp file containing the geometry and data of the coastal system of defensive towers;

- $\quad$ the DTM (Digital Terrain Model) of the coastal band of Sardinia.

The Visibility tool was used in Observer mode, it identifies which observers are visible from each raster surface location. The dataset was divided into groups of up to 16 observers (coastal towers) to accommodate the maximum number of observers allowed by the tool. In this subdivision, in order to guarantee analysis consistency, each group has two towers in common with the adjacent ones.

The analysis performed shows that only 6 coastal towers do not meet the criteria required by the intervisibility design conditions, see Figure 6. These are the coastal towers called Iscra Ruia, Longonsardo, Porto Cervo, Terranova, Sarralà and Chia.

For these towers were also extracted profiles to check constraints and / or the presence of outliers in the DTM, see figures from 7 to 10 .

Basically we can say that, despite not having the modern analysis tools, the defense system of the Royal Administration was designed in a manner consistent with the conditions imposed except for the above mentioned 6 towers.
Regarding the historical analyses performed by Rassu, for two towers his result is not confirmed, specifically Iscra Ruia and Sarrala. Rassu, in fact, says that the tower Iscra Ruia "is visible from the neighboring towers of Foghe to the south and Colombargia to the north"; while the Torre Sarralà "had to complete the system of signal transmission between the Sarrabus and the Ogliastra" (South and North with respect to the tower in question).

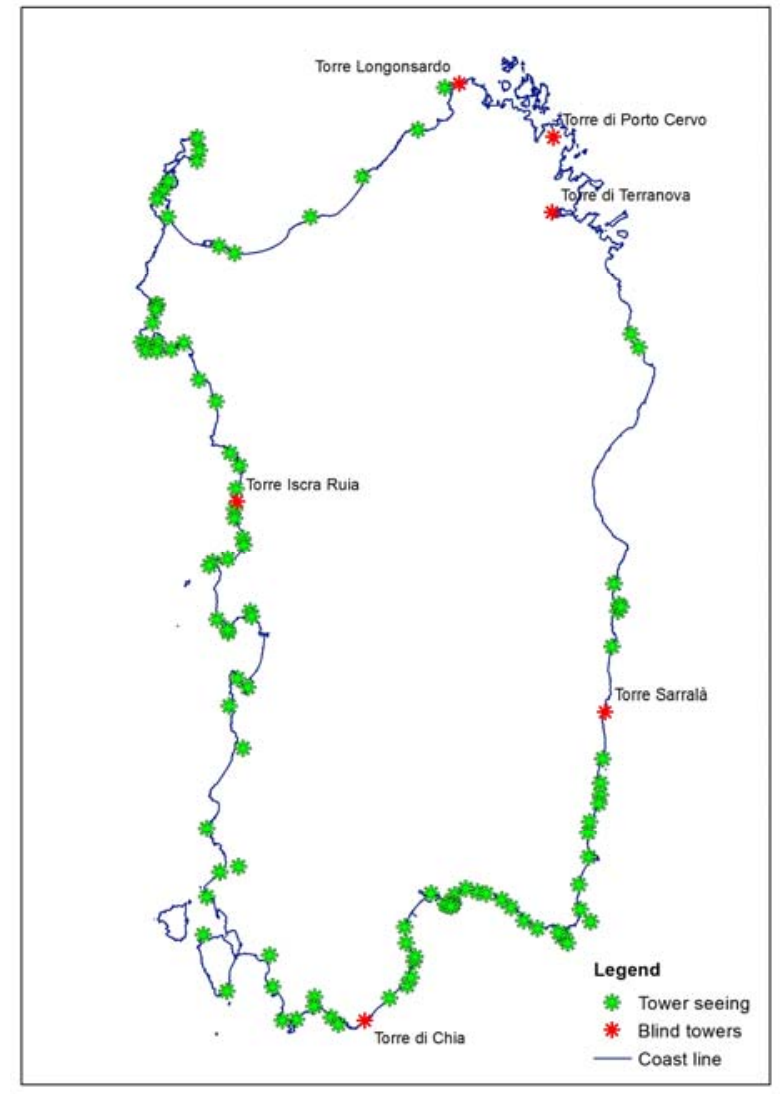

Figure 6: Intervisibility

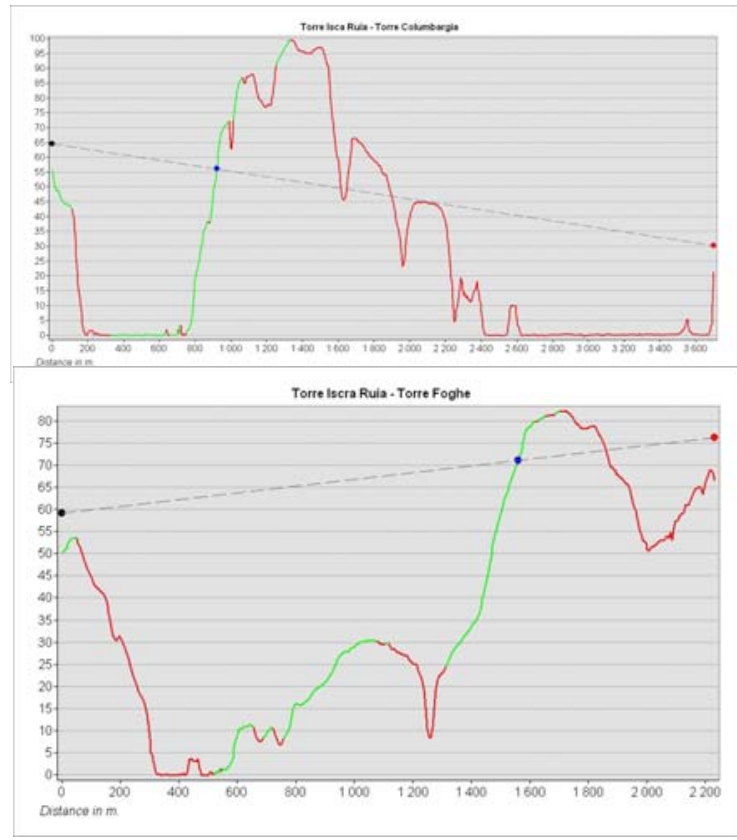

Figure 7 and 8: Altimetry profiles between the Iscra Ruia Tower respectively the previous and next the tower. 

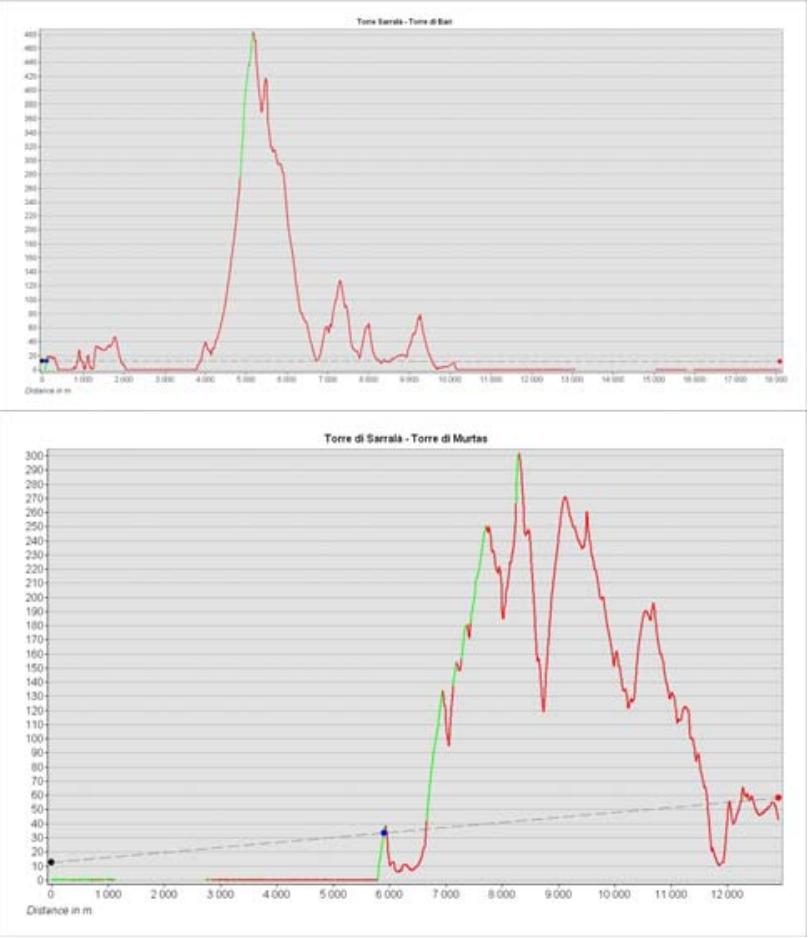

Figure 9 and 10: Altimetry profiles between the Sarralà Tower respectively the previous and next the tower.

In the figure 11 are summarized the intervisibility results obtained from a block of sixteen towers. Each row represents the visibility of one tower and, in particular, we used the green colour for the visible towers and the red colour for the not visible ones.

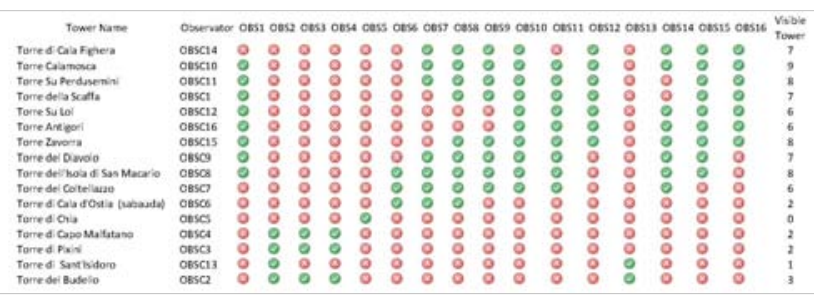

Figure 11: An example of data sheet summarizing the visibility study for a block of sixteen towers.

\subsection{Control over the water supplies}

The second requisite to be verified was related to the control the coastal towers had to keep over all water supplies near the coast, which could become an asset for raiding corsair ships.

The data used were:

- Total_Tower_ETRF2000_3D.shp, the file containing the geometry and data of the coastal system of defensive towers;

- $\quad$ the DTM (Digital Terrain Model) of the coastal band of Sardinia;

- DBT_emergenzanaturaleacqua.shp, the shapefile containing springs, water sources, and river mouths on the coastal band.

The analysis is based on the visibility map of the coastal towers, calculated in the previous phase, here spatially intersected with the water sources shapefile. Figure 12 shows the results, with the water supply points superimposed over the towers' total visible area (in green).

The results of the analysis were less positive than the previous stage: as shown in the figure, many water sources were not visible from any tower.

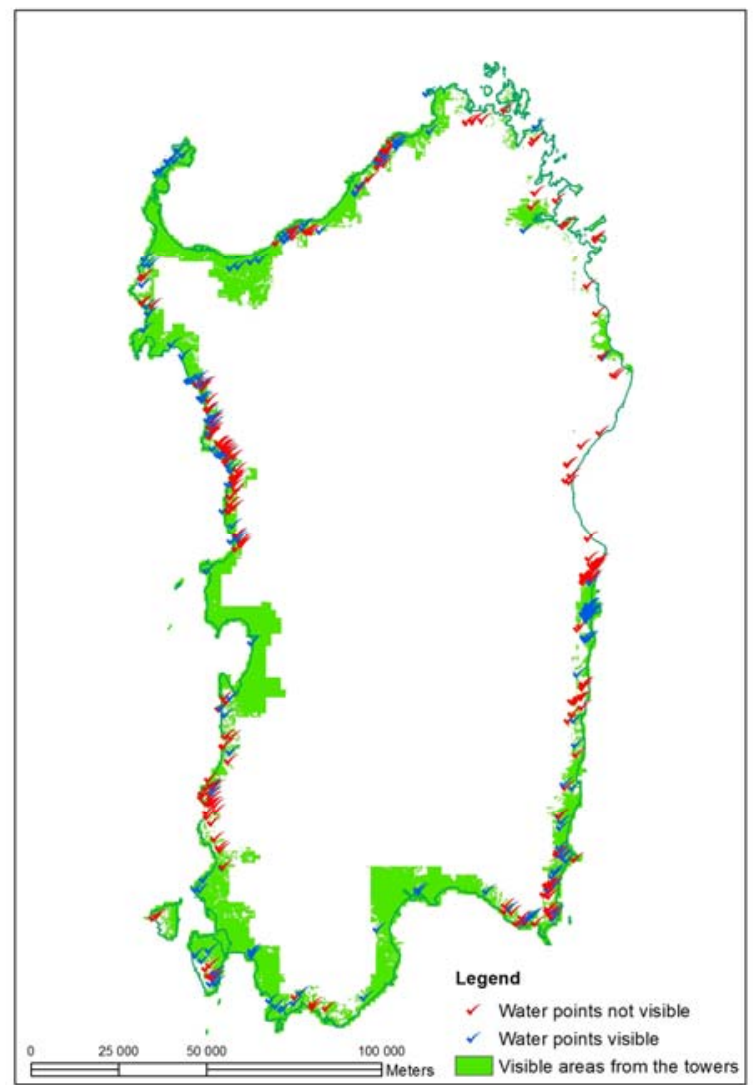

Figure 12: visibility study of the water supply points

\subsection{Control over the coastal caves and inlets}

The third and last requisite to be verified was the one concerning over any coastal cave, inlet or cove that could harbour or hide the corsair ships.

The data used were:

- Total_Tower_ETRF2000_3D.shp, the file containing the geometry and data of the coastal system of defensive towers;

- $\quad$ the DTM (Digital Terrain Model) of the coastal band of Sardinia;

- 1:2000 scale shapefile of the coast line, extracted from the 1-meter resolution DTM of the coastal band.

This analysis was also based on the visibility map of the coastal towers, intersected this time with the coast line. Figure 13 shows (in blue) the portions of coast which are visible from at least one tower, and (in red) those which are occluded.

As evidenced by the figure, three large areas remain exposed: the one north of today's Costa Smeralda, the coast of Ogliastra to the east, and that of the Island of San Pietro to the southwest. It must be noted anyway that much of these coasts are inaccessible from the seas due to their steep orography. 


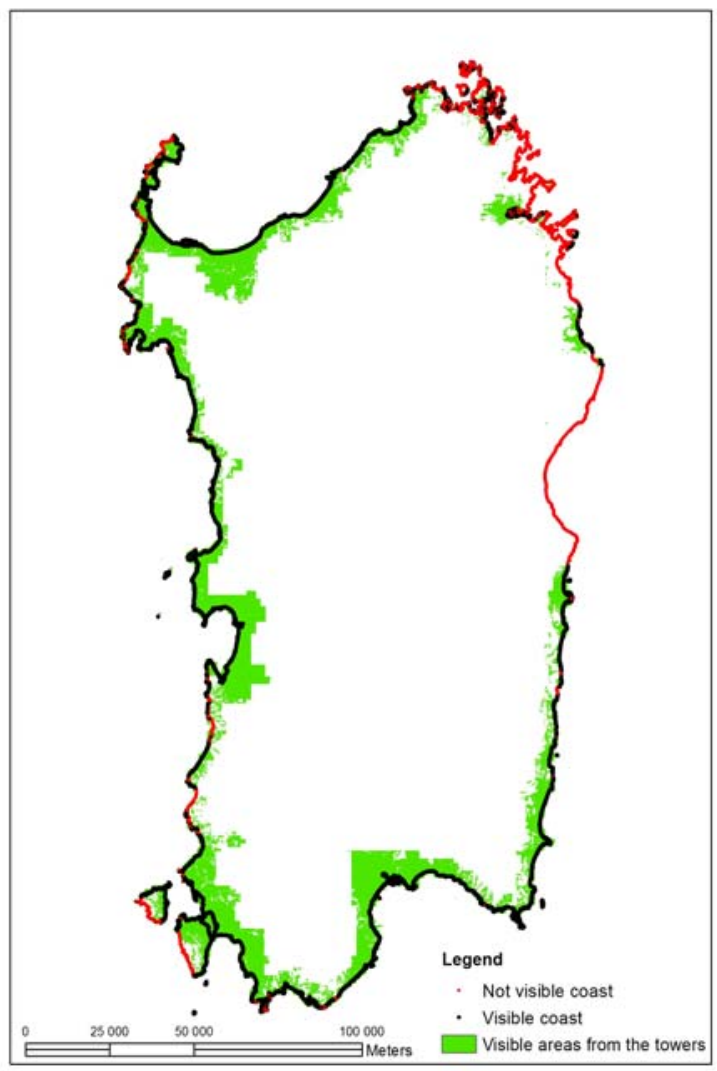

Figure 13: Visibility study of the coast line

\section{CONCLUSION}

The system of the Sardinian coastal towers has always fascinated both the experts of the matter and the laymen. The pivotal position of Sardinia, at the center of the Mediterranean and just a hundred nautical miles from the North African coast, made it a target of corsair and Barbary raids, moreover seeing how, with the winds in their favour, they could reach it in just one day of sailing. The opinions of the foreign onlookers about the system were so favourable, they inspired the development of similar defensive systems in their respective countries: this is how in the $19^{\text {th }}$ century the system of the "Martello Towers" is developed in Great Britain. Despite this interest from multiple parties, serious studies on the argument can be counted on one's hand, and even rarer are those that confront the aspect of the geo-location of the towers.

The study here presented, without having the presumption of being an exhaustive analysis, wants to give its contribution to the knowledge of the coastal defence system by using an objective instrument such as the GIS software.

The objective we posed was to confirm or deny the criteria historians provide as the reason of the presence of towers in these specific locations.

Every GIS study begins with the gathering of data and the design of the database; finding the necessary information required a special attention, due to the scarcity of data and even, in some cases, the contradictions between historical sources.

The study has confirmed, in general, what the historians already affirmed. Conversely, the visibility analysis performed using the GIS brings us to revise the definition of some specific towers and their function in the defence system. This is in particular the case of the tower of Iscra Ruia, historically indicated as the communication semaphore between two parts of Sardinia, Sarrabus and Ogliastra; being indeed blind in respect to other towers, it must have had instead functions of defence of the nearby territory. The same considerations may be made for the towers of Longonsardo and Porto Conte in the north-east of the island. Designed as watch towers for the control of the underlying coasts, they don't actually have any visibility over them. Thus, if a corsair ship managed to get close to the coast without being spotted, it could easily hide in one of the numerous coves that coast offered and then attack from there.

This alternative approach shows how GIS technology can represent a valid tool in support of the analysis of the historical assets, in addition to its natural use in the development of the architectural and environmental ones.

\section{REFERENCES AND BIBLIOGRAPHY}

\section{References from Journals:}

Agosto E. Arddissone P., Rinaudo F. (2007). GIS and Web-GIS, Commercial and Open Source Platforms: General Rules for Cultural Heritage Documentation. International Archives of the Photogrammetry, Remote Sensing and Spatial Information Sciences, vol.XXXVI-5/C53, pp 625-630. ISSN 1682-1750

Droj G. (2010) Cultural Heritage Conservation by GIS. Proceeding of GIS Open 2010 Szekesfehervar. Macaristan (www.geo.info.hu/gisopen/gisopen2010/eloadasok/pdf/droj.pdf) Costamagna E. (2012). GIS 3D: studio e applicazione alla documentazione dei beni culturali. $\mathrm{PhD}$ thesis Politecnico di Torino (http://porto.polito.it/2501445)

Ardissone P., Rinaudo F.: A GIS for the management of historical and archaeological data (Sept. 2005). International Archives Of The Photogrammetry, Remote Sensing and Spatial Information Sciences. vol. XXXVI-5/C34, pp. 612-616 ISSN: 1682-1750.

Brizzi M., D'andrea A., Sepio D., De Silva M., Court S.: Planning a conservation project: the Information System of the Insula Orientalis I at Herculaneum (Sept. 2005). International Archives Of The Photogrammetry, Remote Sensing and Spatial Information Sciences. vol. XXXVI-5/C34, pp. 612-616 ISSN: 1682-1750.

Brumana R. , Achille C., Oreni D., Prandi F.: From the guide of georeferencing Cultural Heritage for the Map of Risk (Regione Lombardia) to the georeferencing and troubleshooting in historical sites (Sept. 2005). International Archives Of The Photogrammetry, Remote Sensing and Spatial Information Sciences. vol. XXXVI-5/C34, pp. 612-616 ISSN: 1682-1750.

\section{References from Books:}

Altara E., Guida alle torri costiere della Sardegna, Cortona 2007.

Montaldo G., Le torri costiere della Sardegna, Roma 1996 Rassu M., Sentinelle del mare. Le torri della difesa costiera della Sardegna, Dolianova (CA) 2005

Sorgia G., La Sardegna spagnola, Sassari 1982 